\title{
Association between Cigarette Smoking History and Mortality in 36,446 Health Examinees in Korea
}

\author{
Kyoungwoo Kim ${ }^{1}$, Taiwoo Yoo $^{2}$, Yeonju Kim ${ }^{3}$, Ji-ho Choi ${ }^{4}$, Seung-Kwon Myung ${ }^{5}$, \\ Sang-Min Park ${ }^{6}$, Yun-Chul Hong ${ }^{3}$, Belong $\mathrm{Cho}^{6}$, Sue K Park ${ }^{3,9}$, Keun-Young Yoo ${ }^{3 *}$
}

\begin{abstract}
Background: It is well known that smoking is a preventable factor for all-cause mortality; however, it is still questionable how many years after smoking cessation that people will have reduced risk for mortality, in particular in those with a high interest in their own health. We aimed to examine the association between time since quitting smoking and total mortality among past-smokers relative to current smokers. Materials and Methods: We enrolled 36,446 health examinees that voluntarily taken with diverse health check-up packages of high cost burden in 1995-2003 and followed them till death by 2004 . The history of cigarette smoking consumption was collected using a self-administrative questionnaire at the first visit time. Mortality risk by smoking cessation years was analyzed using Cox's proportional hazard model. Results: Compared to non-smokers, male smokers over 15 pack-years had higher risk for total mortality $(\mathrm{HR}=1.60,95 \% \mathrm{CI} 1.23-2.14)$. The mortality risk in female smokers with same pack-years was more pronounced than that in male smokers (HR=2.83, 95\% CI 1.17-7.04) despite a small number of cases. Compared to current smokers, a decrease of total mortality was observed among those who ceased smoking, and inverse dose-response was found with years after cessation: RR 0.98 (95\% CI, 0.64-1.41) (<2 yrs), 0.60 (95\% CI, 0.43-0.83) (3-9 yrs), and 0.58 (95\% CI, 0.43-0.79) ( $\geq 10$ yrs). Conclusions: A reduced risk of total mortality was observed after 3 years of smoking cessation. Our findings suggest that at least 3 years of smoking cessation may contribute to reduce premature mortality among Asian men.
\end{abstract}

Keywords: Smoking - smoking cessation - mortality - preventive health services - early detection of cancer

Asian Pac J Cancer Prev, 15 (14), 5685-5689

\section{Introduction}

Smoking is an established risk factor for cancer, cardiovascular, and all-cause mortality, and former smokers are at a lower risk for total mortality compared with continuing smokers in both Western and Asian countries (Huxley et al., 2007); however, the time required to reduce risks and the reduction rate for total mortality differs among studies according to differences in socio-demographic factors, disease prevalence, and smoking rate of the study population (Kim, 2013): The population of some studies was the nurses or doctors and they are different from general populations (Kawachi et al., 1993; Critchley and Capewell, 2003; Doll et al., 2004; Anthonisen et al., 2005).

Nearly half of Korean men still smoke, and the presumed smoking-related morbidity and mortality is high (Oh at al., 2012); however, it is not well known how long it would take for former smokers to get out of the high mortality risk category after smoking cessation in Korean adults.

We attempted to verify not only the total mortality according to smoking status but also the temporal relationship between smoking cessation and decline in mortality risk. We also investigated the different health effect of smoking cessation on reducing mortality in our study group who are expected to have the beneficial health effects by the health screening and promotion programs for asymptomatic adults (Black et al., 2002).

\section{Materials and Methods}

The Health Promotion Center started a routine screening examination and counseling for healthy adults in 1995 at Seoul National University Hospital in Korea as a preventive health service. Based on gender and age, early diagnostic tests are recommended to asymptomatic patients, including anthropometric measurement, blood

${ }^{1}$ Department of Family Medicine, Inje University Seoul Paik Hospital, ${ }^{2}$ Sin-geon-gang-in Center, ${ }^{3}$ Department of Preventive Medicine, ${ }^{6}$ Department of Family Medicine, Seoul National University College of Medicine, ${ }^{4}$ Department of Family Medicine, Inha University Hospital, Incheon, ${ }^{5}$ National Cancer Center, Gyeonggi-do, ${ }^{7}$ Department of Biomedical Science, Seoul National University Graduate School and Cancer Research Institute, Seoul National University, Seoul, Korea*For correspondence: kyyoo@snu.ac.kr 


\section{Kyoungwoo Kim et al}

pressure, serum fasting glucose, cholesterol, complete blood cell count, urine analysis, and cancer screening for the stomach, colon, breast, liver, and uterine cervix. Physicians recommend additional tests based on their symptoms, if any, and high risk subgroups. Between 1995 and October 2003, 22,850 men and 21,771 women visited the center. The mortality of 18,890 men who agreed to participate and completed the self-reporting questionnaire about smoking, alcohol, exercise, and medical history of hypertension and diabetes from May 1995 to October 2003 was observed until December 2004 in this study. The existing health record including mortality data was converted into code deleting personal identifiable information and secondary data was made. The secondary data was analyzed retrospectively.

Men were categorized according to their smoking status as non-smokers, current smokers, or former smokers. Current and former smokers were further asked about the average amount of cigarettes per day, smoking period, time elapsed since quitting, and the average smoking quantity before quitting smoking as continuous variables. Pack-year units were quantified by multiplying the smoking period by average packs of cigarettes to find out the correlation between smoking and total mortality.

The level of alcohol intake was divided according to problem drinking or not, which is defined as alcohol intake of $50 \mathrm{~g}$ or more at a time, or $140 \mathrm{~g}$ per week as measured by a self-reporting questionnaire about the types of liquor, drinking frequency, and average drinks per sitting as continuous variables (National Institute on Alcohol Abuse and Alcoholism, 2005). The regular exercise group was defined as those who exercise 20 minutes or longer at a time on average more than three times a week (Physical Activity Guidelines Advisory Committee, 2008). The degree of obesity was determined by body mass index: underweight was defined as lower than $18.5 \mathrm{~kg} / \mathrm{m}^{2}$, and obesity was defined as $25 \mathrm{~kg} / \mathrm{m}^{2}$ or higher (Oh, 2011). The diabetic group was defined as those who are currently undergoing treatment, or whose fasting blood sugar is above $126 \mathrm{mg} / \mathrm{dl}$ (American Diabetes Association, 2013). The hypertension group was defined as those who are currently undergoing treatment, whose systolic blood pressure is above $140 \mathrm{mmHg}$, or whose diastolic blood pressure is above $90 \mathrm{mmHg}$ (James et al., 2014).

The death of the subjects, which is a consequential variable of this study, was based on the national death data gathered by the National Statistical Office from death certificates, which contain the cause and the date of death. $99.5 \%$ of the national death data was classified by cause of death. These statistics contain information on the address of the deceased, address of the reporter, resident registration number of the deceased, marital status, cause of death, person who diagnosed death, and place of death. The National Statistical Office also announces the number of deaths and standardized mortality rate every year.

To evaluate the impact of smoking while adjusting for age, body mass index, alcohol intake, exercise, and presence of hypertension and diabetes, which may affect mortality, Cox's proportional hazard model was performed using the SPSS 12.0 package software for statistical analysis to determine relative risks and $95 \%$ confidence interval (CI).

\section{Results}

The average age of the study subjects was 49.6 years, and $47.5 \%$ of the men were current smokers. The average age of the current smokers was lower than the nonsmokers, but there was no difference in average body mass index or obesity prevalence rate. A higher percentage of the former smokers exercised regularly, and fewer cases of problem drinking were observed among the current smoker group (Table 1).

The average follow-up period for the target population was 5 years, and 485 total deaths were observed. Of these total deaths, 230 were cancer-related, and 94 were caused by cardiovascular problems. Age-adjusted all-cause mortality rate per 100,000 person-years in this study group was lower by 29 percent of the mortality rate in Korea (Table 2).

The multivariate relative risk for past smokers and current smokers compared with non-smokers was 1.12 (95\%CI, 0.85-1.47) and 1.65 (95\%CI, 1.27-2.15) after adjusting for age, body mass index, regular exercise, problem drinking, and presence of hypertension and diabetes as factors that can affect total mortality.

Table 1. General Characteristics of the Study Population According to Smoking Status

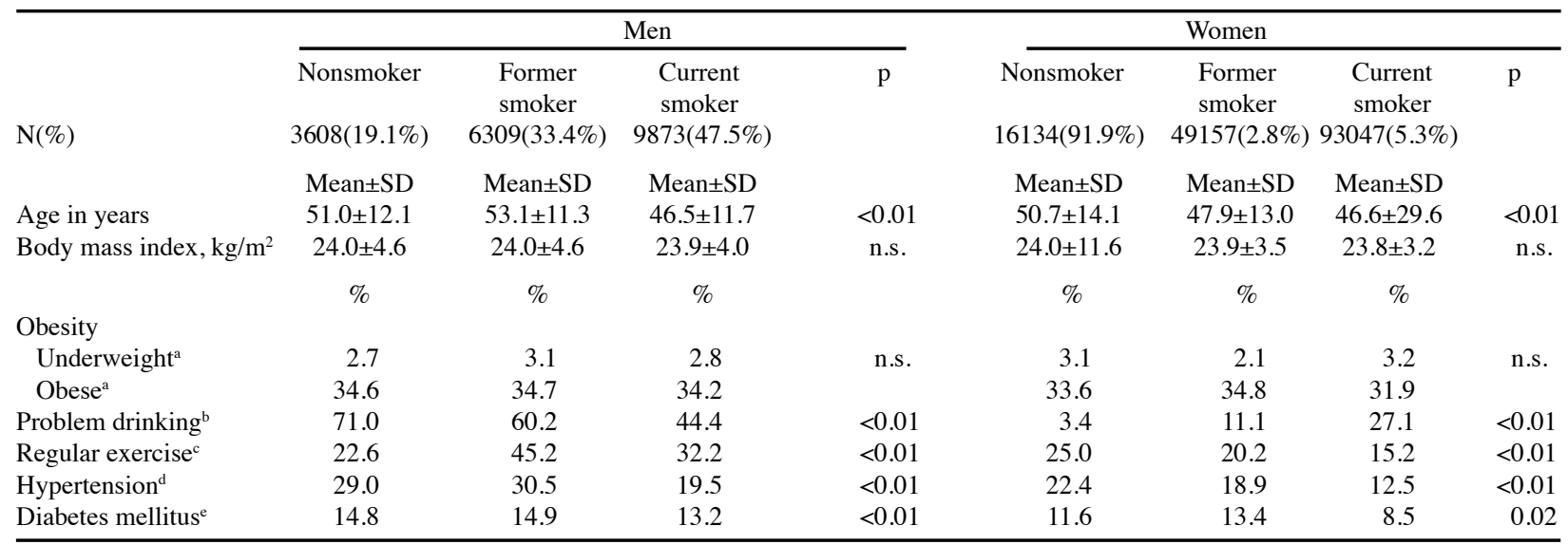

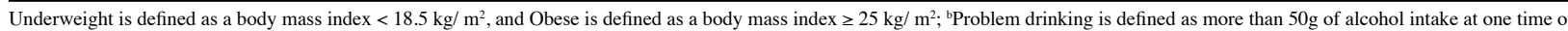
more than $140 \mathrm{~g}$ of alcohol intake in a week in men; ${ }^{\circ}$ Regular exercise is defined as exercise frequency of more than 3 times a week and exercise duration of more than 20 minutes; ${ }^{\mathrm{d}} \mathrm{Hypertension}$ is defined as systolic blood pressure $\geq 140 \mathrm{mmHg}$ or diastolic blood pressure $\geq 90 \mathrm{mmHg}$ or use of anti-hypertensive medication; 'Diabetes mellitus is defined as fasting serum glucose $\geq 126 \mathrm{mg} /$ dl or use of anti-diabetic therapy 
Furthermore, the relative risk for current smokers of less than 15 pack-years was 1.49 (95\%CI, 1.02-2.18) and of more than 15 pack-years was $1.60(95 \% \mathrm{CI}, 1.23-2.14)$ in compared with non-smokers (Table 3 ).

For the effect of smoking on cause-specific mortality, the multivariate relative risk of death by cancer compared with never smokers was 2.30 (95\%CI, 1.32-4.00) in less than 15 pack-year smokers and 1.96(95\%CI, 1.26-3.05) in more than 15 pack-year smokers. In particular, the relative risk of lung cancer mortality was 5.22 (95\%CI, $0.85-32.04)$ and 7.15 (95\%CI, 1.63-31.38), respectively (Supplementary Table 1).

Former smokers were classified by how many years had passed since quitting into the following categories: less than 2 years, 3 to 9 years, and more than 10 years. The relative risk of the total mortality of men whose time elapsed after quitting smoking was less than 2 years compared with current smokers was 0.95 (95\%CI, 0.641.41); however, the relative risk of total mortality of men whose time elapsed after cessation was 3-9 years and

Table 2. Mortality Rate of Health Examinees Registered from the SNUH Health Promotion Center, 1995-2003 and National Population in Korea in Men

\begin{tabular}{|c|c|c|c|c|c|}
\hline \multirow{2}{*}{$\begin{array}{l}\text { Age in } \\
\text { years }\end{array}$} & \multirow{2}{*}{$\begin{array}{l}\mathrm{N} \text { of study } \\
\text { population }\end{array}$} & \multirow{2}{*}{$\begin{array}{c}\mathrm{N} \text { of } \\
\text { deaths }\end{array}$} & \multicolumn{3}{|c|}{ Mortality rate } \\
\hline & & & $\begin{array}{c}\text { Study } \\
\text { population }\end{array}$ & $\begin{array}{c}\text { National } \\
\text { data }\end{array}$ & $\begin{array}{l}\text { Mortality } \\
\text { rate ratio }\end{array}$ \\
\hline $20-24$ & 28 & 0 & 0 & 58.5 & 0 \\
\hline $25-29$ & 131 & 0 & 0 & 74.3 & 0 \\
\hline $30-34$ & 424 & 4 & 188.7 & 95 & 1.99 \\
\hline $35-39$ & 1117 & 8 & 143.2 & 168 & 0.85 \\
\hline $40-44$ & 2370 & 22 & 185.7 & 288.5 & 0.64 \\
\hline $45-49$ & 3105 & 32 & 206.1 & 462.2 & 0.45 \\
\hline $50-54$ & 2575 & 50 & 388.3 & 691 & 0.56 \\
\hline $55-59$ & 2690 & 75 & 557.6 & 984.8 & 0.57 \\
\hline $60-64$ & 2952 & 102 & 691.1 & 1544 & 0.45 \\
\hline $65-69$ & 2089 & 80 & 765.9 & 2494.5 & 0.31 \\
\hline $70-74$ & 882 & 52 & 1179.1 & 4039.6 & 0.29 \\
\hline $75-79$ & 382 & 39 & 2041.9 & 6596.3 & 0.31 \\
\hline $80-84$ & 111 & 12 & 2162.2 & 10814.5 & 0.2 \\
\hline 85 - & 34 & 9 & 5294.1 & 19191.6 & 0.28 \\
\hline Total & 18890 & 485 & 13803.9 & 47502.8 & 0.29 \\
\hline
\end{tabular}

Table 3. Cigarette Smoking Consumption and Cessation Duration for the Risk of All-Cause Mortality in 36,446 Health Examinees Registered from the SNUH Health Promotion Center, 1995-2003

\begin{tabular}{lllll}
\hline & \multicolumn{2}{c}{ Men } & \multicolumn{2}{c}{ Women } \\
& $\mathrm{RR}^{\mathrm{a}}$ & $(95 \% \mathrm{C} . \mathrm{I})$. & $\mathrm{RR}^{\mathrm{a}}$ & $(95 \% \mathrm{C} . \mathrm{I})$. \\
\hline Never smoker & 1 & & 1 & \\
Former Smoker & 1.14 & $(0.86-1.50)$ & 2.10 & $(1.10-4.01)$ \\
Current smoker & & & & \\
$\quad \leq 15$ Pack-Years & 1.49 & $(1.02-2.18)$ & 1.65 & $(0.80-3.36)$ \\
$\quad>15$ Pack-Years & 1.60 & $(1.23-2.14)$ & 2.83 & $(1.17-7.04)$ \\
\hline Current smokers & 1 & & 1 & \\
Smoking cessation duration among former smokers & \\
$\quad$ 2 years & 0.95 & $(0.64-1.41)$ & 1.87 & $(0.41-8.57)$ \\
$3-9$ & 0.60 & $(0.43-0.83)$ & 0.69 & $(0.19-2.45)$ \\
$\geq 10$ & 0.58 & $(0.43-0.79)$ & 0.89 & $(0.19-4.09)$ \\
\hline
\end{tabular}

${ }^{\mathrm{a} M u l t i v a r i a t e}$ relative risk (RR), adjusted for age, problem drinking, regular exercise, body mass index, diabetes, and hypertension
Supplementary Table 1. Cigarette smoking Consumption and Cessation Duration for the Risk of All-Cause Mortality in 36,446 Health Examinees Registered from the SNUH Health Promotion Center, 1995-2003

\begin{tabular}{|c|c|c|c|c|}
\hline & $\mathrm{Mc}$ & & & Vomen \\
\hline & $\mathrm{RR}^{\mathrm{a}}$ & (95\%C.I.) & $\mathrm{RR}^{\mathrm{a}}$ & (95\%C.I.) \\
\hline All-cancer & & & & \\
\hline Never smoker & 1 & & 1 & \\
\hline$\leq 15$ Pack-Years & s amon & current smokers & & \\
\hline & 2.30 & $(1.32-4.00)$ & 0.54 & $(0.08-3.89$ \\
\hline >15 Pack-Years & & & & \\
\hline & 1.96 & $(1.26-3.05)$ & 2.96 & $(0.72-12.18)$ \\
\hline Lung cancer & & & & \\
\hline Never smoker & 1 & & 1 & \\
\hline$\leq 15$ Pack-Years & s amon & current smokers & & \\
\hline & 5.22 & $(0.85-32.04)$ & NA & \\
\hline$>15$ Pack-Years & & & & \\
\hline & 7.15 & $(1.63-31.38)$ & 12.98 & $(1.62-104.2)$ \\
\hline Total cardiovascu & lar dis & ases & & \\
\hline Never smoker & 1 & 1 & & \\
\hline$\leq 15$ Pack-Years & s amon & current smokers & & \\
\hline & 0.86 & $(0.33-2.22)$ & 3.51 & $(1.01-11.44)$ \\
\hline$>15$ Pack-Years & & & & \\
\hline & 1.44 & $(0.81-2.57)$ & 3.01 & $(0.41-22.15)$ \\
\hline Hemorrhagic stro & & & & \\
\hline Never smoker & 1 & & 1 & \\
\hline$\leq 15$ Pack-Years & s amon & current smokers & & \\
\hline & 0.78 & $(0.79-7.78)$ & 3.94 & $(0.51-30.31)$ \\
\hline >15 Pack-Years & & & & \\
\hline & 2.13 & $(0.55-8.30)$ & NA & \\
\hline Ischemic stroke & & & & \\
\hline Never smoker & 1 & & 1 & \\
\hline$\leq 15$ Pack-Years & s amon & current smokers & & \\
\hline & 2.04 & $(0.33-12.78)$ & 6.36 & $(0.77-52.67$ \\
\hline$>15$ Pack-Years & & & & \\
\hline & 0.75 & $(0.16-3.52)$ & 14.78 & $(1.78-122.8)$ \\
\hline
\end{tabular}

${ }^{a}$ Multivariate relative risk, adjusted for age, body mass index, problem drinking, regular exercise, diabetes, and hypertension

more than 10 years were $0.60(95 \% \mathrm{CI}, 0.43-0.79)$ and 0.58 (95\% CI, 0.43-0.79), compared with current smokers (Table 3).

\section{Discussion}

We identified the association between cigarette smoking and mortality in health examinees although the mortality of this study population was lower than that of general population. The early detection of diseases itself could not offset the smoking hazards. Unlike other community-based or health-related workers' studies, this study population had different characteristics. Participants in this study are those who want to get screening tests with diverse screening packages such as various imaging screening, 50-200 clinical laboratory tests including cancer antigens and markers, measurement of physical health, etc, and voluntarily visited to big university hospital despite of high cost burden. Although complementary biannual basic health check-up system for all Korean people adults at age 40 is free under full coverage of Korea National Health Insurance, this diverse screening ask the persons a great deal of money $(\$ 500-5,000)$ though it is relatively 
chief compared to the health check-up cost in developing countries. Therefore, these study participants have a higher interest in their own health, less health-threatening behaviors, and obtain the benefit of earlier diagnosis of disease than the general population. Moreover, they had a greater opportunity to learn healthier life styles than the general population because the physicians would clinically intervene to improve health-threatening factors through early screening and medical treatment. This study population of the Health Promotion Center had lower mortality rate than overall Korean population by one-third. Nevertheless, cigarette smoking is still an important risk factor for increased risk for mortality in this population.

We did not observe a decrease in all-cause mortality in relation with the time elapsed after quitting in women. The respective percentages of non-smokers, past smokers, and current smokers in women in our study population were $91.9 \%, 2.8 \%$, and $5.3 \%$. The percentage of female smokers and the follow-up period were not large and long enough to observe statistically significant results for the effect of smoking cessation on the decrease of mortality (Kang et al., 2013). In the Nurses' Health Study which observed 117,001 women for 12 years, the percentages of never smokers, past smokers, and current smokers were $43.3 \%, 23.5 \%, 33.2 \%$ respectively at the start of the study (Kawachi et al., 1993).

We could not exclude the "Ill Quitter" effect in this study population. The smokers quit smoking because they are diagnosed with a smoking related disease, such as cardiovascular disease or cancer. The prevalence of hypertension and diabetes in former smokers was higher than in current smokers. Ill quitter effect might lead to an underestimation of the relative risk of total mortality by smoking and the decline by cessation, especially among those who had stopped smoking for less than 2 years. The decline of all-cause mortality among former smokers might have been more significant if we could have adjusted for this effect.

The British Doctors' Cohort observed 34,439 male doctors born between 1851 and 1930 for 50 years from 1951 , and they reported that a substantial progressive decrease in the mortality rates among non-smokers over the past half century (due to prevention and improved treatment of disease) had been wholly outweighed (Doll et al., 2004). The relative risk of lung cancer mortality in smokers versus non-smokers was 14.9 times in the 50 years follow-up, which was 8.0 times in the 20 years observation. Further, it was also reported that the death rate of smokers was about three times as high as that of non-smokers for those born around 1920, while the death rate of smokers was about twice as high as that of nonsmokers for those born from 1900 to 1909. This suggests that the more developed medical technology becomes, the higher the relative risk of death becomes for smokers. Considering the relatively short follow-up period and the ill quitter effects, the relative risk of total mortality by smoking in this study population might be underestimated.

This study observed a decrease in mortality, not the disease. Those who did not die even if afflicted by a disease were not included. Cancer or cardiovascular disease can be curable, and their complications and mortality can be prevented and delayed by early diagnosis and intervention. Mortality can be also be influenced by socio-economic status and accessibility to medical care. However, as shown by a study that found that smoking also decreased the survival of cancer patients (Park et al, 2006), the development of medical technology is expected to provide more benefits to non-smokers than smokers, and the relative health hazard of smoking will be greater.

The smoking rate in Korean men is $52 \%$ and the success rate of long-term smoking cessation does not seem to be satisfactory even with aid of drugs (Simon et al., 2004; Etter and Stapleton, 2006). More effective strategies for smoking cessation must be developed ( $\mathrm{Su}$ et al., 2012; Jayakrishnan et al., 2013)

Periodic screening tests are important to reduce premature mortality but tests itself have the limited benefits to smokers. However screening program might be a great opportunity for smokers to stop smoking. Physicians always remind smokers who visited for screening tests of the health benefits of stop smoking and struggle for individualized effective strategies for strong motivation.

Our results support the importance of smoking cessation strategies as primary prevention methods to prevent premature mortality by identifying mortality in relation to smoking and the health benefits from smoking cessation of more than 3 years' duration in this study group that received preventive health services.

\section{Acknowledgement}

This work was supported by the 2008 Inje University research grant.

\section{References}

American Diabetes Association (2013). Standards of medical care in diabetes--2013. Diabetes Care, 36, 11-66.

Anthonisen NR, Skeans MA, Wise RA, et al (2005). The effects of a smoking cessation intervention on 14.5-year mortality: a randomized clinical trial. Ann Intern Med, 142, 233-9.

Black WC, Haggstrom DA, Welch HG (2002). All-cause mortality in randomized trials of cancer screening. $J$ Natl Cancer Inst, 94, 167-73.

Critchley JA, Capewell S (2003). Mortality risk reduction associated with smoking cessation in patients with coronary heart disease: a systematic review. JAMA, 290, 86-97.

Doll R, Peto R, Boreham J, Sutherland I (2004). Mortality in relation to smoking: 50 years' observations on male British doctors. BMJ , 309, 901-11.

Etter JF, Stapleton JA (2006). Nicotine replacement therapy for long-term smoking cessation: a meta-analysis. Tobacco Control, 15, 280-5.

Huxley R, Jamrozik K, Lam TH, et al (2007). Impact of smoking and smoking cessation on lung cancer mortality in the AsiaPacific region. Am J Epidemiol, 165, 1280-6.

James PA, Oparil S, Carter BL, et al (2014). 2014 evidencebased guideline for the management of high blood pressure in adults: report from the panel members appointed to the Eighth Joint National Committee (JNC 8). JAMA, 311, 507-20.

Jayakrishnan R, Mathew A, Uutela A, Auvinen A, Sebastian $P$ (2013). Multiple approaches and participation rate for a 
community based smoking cessation intervention trial in rural Kerala, India. Asian Pac J Cancer Prev, 14, 2891-6.

Kang HG, Kwon KH, Lee IW, et al (2013). Biochemicallyverified smoking rate trends and factors associated with inaccurate self-reporting of smoking habits in Korean women. Asian Pac J Cancer Prev, 14, 6807-12.

Kawachi I, Colditz GA, Stampfer MJ, et al (1993). Smoking cessation in relation to total mortality rates in women: a prospective cohort study. Ann Intern Med, 119, 992-1000.

Kim H(2013). The national "smoking cessation clinics" program in the Republic of Korea: socioeconomic status and age matter. Asian Pac J Cancer Prev, 14, 6919-24.

National Institute on Alcohol Abuse and Alcoholism (2005). Helping patients who drink too much: a clinician's guide. Rockville, MD: U.S. Department of Health and Human Services.

Oh IH, Yoon SJ, Yoon TY, et al (2012). Health and economic burden of major cancers due to smoking in Korea. Asian Pac J Cancer Prev, 13, 1525-31.

Oh SW (2011). Obesity and metabolic syndrome in Korea. Diabetes Metab J, 35, 561-6.

Park SM, Lim KM, Shin SA, Yun YH (2006). Impact of prediagnosis smoking, alcohol, obesity, and insulin resistance on survival in male cancer patients: national health insurance corporation study. J Clin Oncol, 24, 5017-24.

Physical Activity Guidelines Advisory Committee (2008). Physical Activity Guidelines Advisory Committee Report, 2008. Washington, DC: U.S. Department of Health and Human Services.

Simon JA, Duncan C, Carmody TP, Hudes ES (2004). Bupropion for smoking cessation: a randomized trial. Arch Intern Med, 164, 1797-1803.

Su TT, Sallehuddin BA, Murniati HH, et al (2012). Factors associated with success or failure of quit attempts: a clinical approach for lung cancer prevention. Asian Pac J Cancer Prev, 13, 175-9. 